\title{
“Unorthodox Rules”: The Instructive Potential of BDSM Consent for Law
}

\author{
Theodore Bennett \\ University of Western Australia \\ theodore.bennett@uwa.edu.au
}

\section{Introduction}

In the case of Doe v George Mason University (2016) a Virginia District Court recently held that BDSM activities were not protected by the right to sexual liberty provided by the Constitution's due process clause. This was because BDSM activities were said to involve "inherent risks to personal safety not present in more traditional types of sexual activity", and therefore states can restrict such activities because they have an "interest in the protection of vulnerable persons” (Doe v George Mason University, 2016, p. 45). This case's emphasis on the potential "dangerousness" of BDSM embodies sex-negative reasoning in that it frames BDSM "sexuality and sexual practices primarily as risky" and "difficult to manage" (Williams et al, 2015, p. 6). This type of reasoning is not unique to this case but instead reflects the sex-negativity of the broader legal approach to BDSM (Kaplan, 2014). Law has historically treated BDSM as a type of dangerous "violence” rather than sex (Hanna, 2000-2001) and has criminalized injurious BDSM activities despite the consent of participants (Ridinger, 2006; Kaplan, 2014; Haley, 2015). That consent typically makes other "violent" injurious activities lawful, such as body modification and contact sports (Weinberg, 2016), reveals that BDSM is nevertheless treated differently due to a negative evaluation of its perceived sexual “immorality” (Egan, 2007) and “deviance” (Kaplan, 2014, pp. 137-138).

This paper seeks to break with the current legal approach and follows Kaplan's (2014) lead by instead adopting a sex-positive legal approach to BDSM. One aspect of a sexpositive approach to BDSM is the recognition of the "unique benefits" (Kaplan, 2014, p. 23) and "inherent strengths" of BDSM as a type of sexuality (Williams et al, 2015, p. 7). In particular, this paper identifies that a key strength of the BDSM sexual culture is the nuanced manner in which it deals with consent, and this paper proposes that legal thinking around sexual consent can learn much from the mechanisms of BDSM consent. The notion that discussions of BDSM consent have "value ... beyond BDSM communities” (Barker, 2013, p. 901) echoes through the remarks of a number of commentators. Academics have suggested that "BDSM-type consent guidelines could be useful in vanilla relationships" (Beres \& MacDonald, 2015, p. 428), that they make consent "much clearer than in the normative world" (Haviv, 2016, p. 285), and that they promote more open communication between partners (Egan, 2007, p. 1618). Even Hanna, in the midst of her protracted defense of the current strict legal prohibitions on BDSM activities, admits that "[t]hose who engage in safe and consensual S/M have much to teach the rest of us about what consent really means" (Hanna, 2000-2001, p. 247). This paper extends this line of thought by charting the conceptual links between legal models of sexual consent and the specific mechanisms of BDSM consent. 


\section{Criminal Law and Consent}

To consent to a proposed course of activities is generally understood as being to agree, or acquiesce, to them (Weinberg, 2016, p. 7). Consent is important to many different criminal offences, for example the presence/absence of consent "marks the difference between borrowing and stealing" and "between rape and a welcomed sexual encounter" (Weinberg, 2016, p. 7). Because BDSM has been understood by the law to involve violence, consent to BDSM activities has historically been engaged with by courts and legal commentators in the context of “violent consent” (Hanna, 2000-2001, p. 240). Legal discussions of BDSM consent have thus typically revolved around consent in the context of violent offences involving assault, battery and physical injury. However, this paper's turn towards a sex-positive approach that values BDSM as a type of sexuality enables broader discussion around BDSM consent in the context of "sexual consent" as well (Hanna, 20002001, p. 240).

Consent is fundamentally important to the way that law regulates sexual activities. The absence of consent is a key element of many sex offences, including sexual assault and rape (Decker \& Baroni, 2012). What exactly is required for legally-recognized "consent" to sex has been the subject of much contestation and renegotiation within legal thinking. The law historically has been dominated by a “"No' Model” of sexual consent under which sexual activity is taken to be consensual as long as it is not the result of force, and there is no verbal indication of non-consent nor any physical resistance (Anderson, 2005, p. 1409). However, the role of consent within laws around sexual offending has 'evolved' over time (Yung, 2015-2016, p. 5), and in recent decades a variety of alternative models of sexual consent have been suggested by commentators and adopted piecemeal into various laws and policies across America (see Decker \& Baroni, 2012; Gersen \& Suk 2017). This paper will chart the links between BDSM consent and these different models of sexual consent, and will demonstrate the particular strength and sophistication of the BDSM model.

\section{Mechanisms of BDSM Consent}

Consent lies at the "heart" of BDSM activities (Williams et al, 2014). While there “are a variety of S\&M worlds", and "tremendous diversity among groups as well as individuals in terms of their preferences and tastes", there are also clear "commonalities" (Weinberg, 1995, p. 290). Sisson (2007) identifies a "sexual culture" as having emerged from the various BDSM communities and organizations within North America. The conception of a "sexual culture" reflects the points of connection across the BDSM subcultures around issues such as "establish[ed] codes of behaviour' and 'system[s] of shared meanings" (Sisson, 2007, p. 25). Consent is a central connecting concept with the BDSM sexual culture and is reflected in the various community mantras that guide BDSM activities such as SSC (Safe, Sane and Consensual), RACK (Risk Aware Consensual Kink), and the newlyproposed 4Cs (Caring, Communication, Consent and Caution) (Williams et al, 2014). The BDSM sexual culture has also developed practical mechanisms around consent that are "de rigueur” for BDSM participants to utilize, and these include negotiations, safewords and aftercare (Sisson, 2007, p. 26). 


\section{Negotiations}

BDSM participants will typically communicate about consent prior to engaging in BDSM activities. Such negotiations can take the form of a singular exchange lasting a "few minutes" or can comprise multiple exchanges over “days or weeks” (Weinberg, 2016, pp. 5456), and can take place by way of free-flowing conversations through to the more formalized checklists (Holt, 2016, p. 924). Negotiations will typically cover issues such as a general outline of the activities to be engaged in, each participants" "limits" (what they are unwilling to engage in), the kinds of activities they enjoy, any relevant health issues that may impact on the activities, and the setting of a safeword (Beres \& MacDonald, 2015; Haviv, 2016; Holt; 2016; Kaak, 2016). Negotiations are considered "an important part of establishing a relationship” between BDSM participants (Moser \& Kleinplatz, 2007, p. 38) and are a predicate of what the BDSM sexual culture considers “[a]cceptable BDSM” (Williams et al, 2014). Negotiations will generally be more in-depth and prolonged where participants have not played with each other before and may be less formal or truncated where participants have a shared history of negotiated play, for example when the participants are in an ongoing relationship (Newmahr, 2011, p. 75).

The BDSM sexual culture's practice of negotiations stands in stark contrast to broader society where consent to sexual activities is "often not discussed at length between partners” (Pitagora, 2013, p. 27). BDSM sexual culture’s direct engagement with consent during negotiations can help defuse the potential for miscommunication and exploitation. Whereas some sexual communication may rely on body language and non-verbal cues, gendered behavioral expectations and other ambiguous/subtle social indicators to communicate sexual interest, negotiations involve explicit communication about proposed activities and thus may minimize the risk of one participant misinterpreting the other's consent. This is because "[t]he act of explicitly communicating and agreeing upon mutually understood parameters clarifies those parameters in a way that implied understanding cannot" (Pitagora, 2013, p. 34). The direct nature of negotiations accords with "affirmative" models of sexual consent that have been championed by some legal commentators (Klement et al, 2017, pp. 130-131). Breaking with the historical “'No' Model” of consent, under affirmative models of consent (see e.g., Remick, 1993; Anderson, 2005) it is not enough for a person to claim that their partner was consenting, or that they thought their partner was consenting, because of an "absence of resistance or refusal” by their partner (Beres \& MacDonald, 2015, p. 419). Instead, consent to sex under an affirmative model of consent can only be established through "a positive indication that both people want to engage in sex" (Beres \& MacDonald, 2015, p. 419) such as verbal agreement (Remick, 1993). Negotiations reflect this affirmative model by requiring positive pre-indication of consent and correlatively embedding the notion that a lack of communication about non-consent is not tantamount to consent.

Negotiations also "unbundle” consent (Gersen \& Suk, 2017, p. 150), that is they specify the particular activities that BDSM participants are consenting to when they give their consent. Even where a person gives their consent to sexual activity with a clear nod or a "Yes" it can be difficult to determine the "scope" of their consent (Gersen \& Suk, 2017, p. 15). Does their consent cover heavy petting? Oral, vaginal or anal sex? Being tied up and 
spanked? Some combination of the preceding options? Consent to sexual activity of some kind is not consent to sexual activity of every conceivable kind. To operate on the basis of the "exclusionary principle ... that as long as neither participant withdraws their consent, all actions can be assumed to be consensual" is neither a safe nor a respectful way to manage a sexual encounter (Tsaros, 2013, p. 865). Negotiations bypass this potential issue as BDSM participants explicitly 'unbundle' their consent by specifying both what they are consenting to as well as the limits of their consent.

\section{Safewords}

During negotiations BDSM participants typically set a "safeword”. Participants may generate their own idiosyncratic safeword, adopt "ubiquitous or accepted" community safewords, or be required to use a "house safeword" at a particular club or party (Newmahr, 2011, pp. 75-86). A safeword can be a literal word (such as “red”) or participants may alternatively agree upon a non-word verbal noise (such as repeated "uh-uh") or a non-verbal signal (such as dropping a clutched object) if their proposed BDSM activities involve head/mouth restraints. Where a participant uses a safeword they are communicating that they want the current BDSM activities to end immediately.

Safewords are another powerful mechanism for ensuring consent. Safewords reflect a conceptual model of consent that does not treat consent-giving as a singular event - a oneoff "Yes"/"No" - but rather as an ongoing process where consent can be "rescinded at any time” (Pitagora, 2013, p. 32). Like negotiations, safewords can short-circuit potential issues with sexual miscommunications around consent by providing a pre-agreed and unequivocal method for communicating the withdrawal of consent. American laws around sexual consent have struggled with the issue of withdrawing consent. The phenomenon termed "postpenetration rape", that is where penetrative sex begins with consent but then continues despite one party no longer consenting, does not necessarily constitute the legal offense of rape (McLellan, 1990-1991). Criminal laws, unlike BDSM models of consent, have historically held that once consent to sex is given and penetration occurs such consent effectively cannot be withdrawn until the point at which penetration ends (McLellan, 19901991). Despite the fact that some states have now moved to cover post-penetration with their rape law provisions (Parker, 2012, pp. 1073-1081), legal problems remain with determining where and when consent has been successfully withdrawn during sex (Fradella \& Brown, 2005, pp. 15-17; Parker, 2012). Legal commentators have recognized that mistakes, even "reasonable mistakes", about sexual communication are, unfortunately, "entirely commonplace” (Schulhofer, 1998, p. 65). When communications about consent take place in the middle of sexual activities the risk of miscommunication may be heightened. By providing participants with "a language, a common understanding, a convention jointly created in advance" (Soble, 2008, p. 466), safewords generate clarity and unambiguity around consent for the entire duration of BDSM activities.

\section{Aftercare}

Aftercare is something that "occurs regularly" as part of BDSM practice (Pitagora, 2013, p. 29). Aftercare is a specially managed "process of 'coming down"” (Beckmann, 
2004, p. 198) from the emotional and physical experience of BDSM activities and is typically (though not necessarily exclusively) focused on participants who take on a bottom/submissive/masochistic role within the activities (Newmahr, 2011, p. 76). Aftercare can incorporate elements of both physical and emotional support, and can include the provision of hydration/food, reassuring contact such as "caressing, stroking, cuddling" (Newmahr, 2011, p. 76), and communication (Sagarin, 2009, p. 190). Aftercare processes come in "varying intensities and manifestations" (Pitagora, 2013, p. 29), and the "desire for aftercare differs by person as well as by scene” (Newmahr, 2011, p. 76).

Legal models of consent to sex typically place no importance on the time period after the sexual activities in question, and retrospective grants or withdrawals of consent to sex ordinarily have no legal effect (Gersen \& Suk, 2017, pp. 159-161). However, aftercare is an extension of the "cognitive arc” of a participant's consent to BDSM activities (Pitagora, 2013, p. 29). Even though BDSM activities may have ceased, their after-effects can linger for some time as participants process the "physiological stress" (Sagarin et al, 2009) and "altered states of consciousness" that can occur during BDSM activities (Ambler et al, 2017). Aftercare recognizes these after-effects and reflects the fact that when BDSM participants consent they agree to take on a certain amount of "responsib[ility] for the welfare" of each other (Newmahr, 2011, p. 76). As Beckmann (2004, p. 198) identifies, such responsibility embeds a broader ethics of care within BDSM activities which, in turn, reflects a model of consent based on "communicative sexuality." Communicative sexuality proposes that sexual interactions be seen more like conversations than contracts, with our understandings of consent adjusted accordingly (Pineau, 1989, p. 233). If we assume that within sexual interactions, like conversations, "each person enters the encounter in order to seek ... satisfaction' then 'each person engaging in the encounter has an obligation to help the other[s] seek [their] ends” (Pineau, 1989, p. 234). Rather than understanding consent to sex as a deal that can be agreed/refused by a simple "Yes"/“No" communication, communicative sexuality understands consent to sex as something that emerges from the mutuality of a sexual encounter. Negotiations are the initial means by which BDSM participants engage in mutuality through the sharing of what they dis/like, the use of safewords reflects mutuality through ongoing communication (Pineau, 1989, p. 242), and aftercare demonstrates the follow-through of mutuality as participants continue to manage each other's satisfaction even after BDSM activities have ceased.

\section{Conclusion}

Although this article focuses on the strengths of the BDSM model of consent it must also be acknowledged that the BDSM sexual culture is not a "perfect world" (Beckmann, 2004, p. 202). Consent is still a "messy business" even for BDSM practitioners (Williams et al, 2014). As with vanilla sexual activities, consent violations (both accidental and intentional) can and do occur in BDSM activities (Wright, Stambaugh \& Cox, 2015). The BDSM model of consent also has room for development. For example, by focusing on managing consent at the level of individual interactions it arguably overlooks the contextual factors that go into shaping consent at a broader social level (Barker, 2013; Beres \& MacDonald, 2015). Yet these criticisms connect back to another key aspect of consent within the BDSM sexual culture: the difficulties involved in managing consent are a point of 
reflexive, ongoing community conversation (Barker, 2013). And, even if nothing else, the BDSM sexual culture's consent mechanisms provide participants with heightened "selfawareness” about consent (Pitagora, 2013, p. 34).

Where the Court in Doe v George Mason University (2016) briefly touched on the issue of consent it observed that "unorthodox rules" governed the "BDSM relationship" between the parties (p. 25), including the use of a safeword (p. 5). The mechanisms by which the BDSM sexual culture manages consent — such as negotiations, safewords and aftercaremay prima facie seem "unorthodox" from the sex-negative legal perspective that has historically condemned BDSM activities as a type of violence. However, this article has argued that, on consideration of BDSM activities as a type of sex, these mechanisms are revealed as reflecting familiar and sophisticated models of legal thinking around sexual consent, including affirmative consent, the unbundling of consent, consent as an ongoing process and communicative sexuality. Legal thinking around sexual consent has much to gain from the links with BDSM consent that this article has begun the process of charting. For example, commentators have struggled with assessing the feasibility of legal models that require explicit discussion of sexual consent prior to any sexual activities; there are concerns about whether this would "ruin the moment" (Remick, 1993, p. 1148) and be impractically unsexy (Anderson, 2005, pp. 1436-1437; Weinberg, 2016, p. 101). However, acknowledgement of the role of negotiations within BDSM clearly demonstrates that prediscussions about consent can be a practicable community norm. Law then has much to gain by adopting a sex-positive approach that recognizes consent as a key strength of BDSM sexuality and that accordingly allows its instructive potential to be unlocked.

\section{References}

Ambler, J. K., Lee, E. M., Klement, K. R., Leowald, T., Comber, E. M., Hanson, S. A., Cutler, B., Cutler, N., \& Sagarin, B. J. (2017) Consensual BDSM facilitates rolespecific altered states of consciousness: A preliminary study. Psychology of Consciousness: Theory, Research and Practice, 4(1), 75-91.

Anderson, M. J. (2005) Negotiating sex. Southern California Law Review, 78, 1401-1438.

Barker, M. (2013) Consent is a grey area? A comparison of understandings of consent in Fifty Shades of Grey and on the BDSM blogosphere. Sexualities, 16(8), 896-914.

Beckmann, A. (2004) "Sexual rights" and "sexual responsibilities" within consensual "S/M" practice. In M. Cowling \& P. Reynolds (Eds.). Making sense of sexual consent (pp. 195-208). Burlington, VT: Ashgate Publishing.

Beres, M. A. \& MacDonald, J. E. C. (2015)

Talking about sexual consent: heterosexual women and BDSM. Australian Feminist Studies, 30(86), 418432.
Decker, J. F. \& Baroni, P. G. (2012) “No” still means "yes": The failure of the "nonconsent" reform movement in American Rape and Sexual Assault law. The Journal of Criminal Law \& Criminology, 101(4), 1081-1169.

Egan, K. (2007) Morality-based legislation is alive and well: Why the law permits consent to body modification but not sadomasochistic sex. Albany Law Review, 70, 1615-1642.

Fradella, H. F., \& Brown, K. (2005) Withdrawal of consent post-penetration: Redefining the law of rape. Criminal Law Bulletin, 41(1), 3-23.

Gersen, J. E., \& Suk, J. (2017) Timing of consent. In F. Fagan \& S. Levmore (Eds.), The timing of lawmaking (pp. 149-170). Northampton, MA: Edward Elgar Publishing.

Haley, D., (2015) Bound by law: A roadmap for the practical legalization of BDSM. Cardozo Journal of Law \& Gender, 21, 631-655. 
Hanna, C. (2000-2001) Sex is not a sport: Consent and violence in criminal law. Boston College Law Review, 42, 239-290.

Haviv, N. (2016) Reporting sexual assaults to the police: The Israeli BDSM community. Sexuality Research and Social Policy, 13, 276-287.

Holt, K. (2016) Blacklisted: Boundaries, violations, and retaliatory behavior in the BDSM community. Deviant Behavior, 37, 917930.

John Doe v. The Rectors and Visitors of George Mason University et. al. (2016) U.S. District Court for the Eastern District of Virginia, 149 F. Supp. 3d 602.

Kaak, A. (2016) Conversational phases in BDSM pre-scene negotiations. Journal of Positive Sexuality, 2, 47-52.

Kaplan, M. (2014) Sex-positive law. New York University Law Review, 89, 89-164.

Klement, K. R., Sagarin, B. J., \& Lee, E. M. (2017) Participating in a culture of consent may be associated with lower rape-supportive beliefs. The Journal of Sex Research, 54(1), 130-134.

McLellan, A. (1990-1991) Post-penetration rapeincreasing the penalty. Santa Clara Law Review, 31, 779-808.

Moser, C., \& Kleinplatz, P. J. (2007) Themes of SM expression. In D. Langdridge \& $\mathrm{M}$. Barker (Eds.), Safe, sane and consensual: Contemporary perspectives on sadomasochism (pp. 35-54). New York, NY: Palgrave Macmillan.

Newmahr, S. (2011) Playing on the edge: Sadomasochism, risk, and intimacy. Bloomington, IN: Indiana University Press.

Parker, S. O. (2012-2013). No means no... sometimes: Developments in postpenetration rape law and the need for legislative action. Brooklyn Law Review, 78(3), 1067-1095.

Pineau, L. (1989) Date rape: A feminist analysis. Law and Philosophy, 8, 217-243.

Pitagora, D. (2013) Consent v coercion: BDSM interactions highlight a fine but immutable line. The New School Psychology Bulletin, 10(1), 27-36.

Remick, L. A. (1993) Read her lips: An argument for a verbal consent standard in rape. University of Pennsylvania Law Review, 141, 1103-1151.

Ridinger, R. B. (2006) Negotiating limits: The legal status of SM in the United States. In P J Kleinplatz \& C Moser (Eds.),
Sadomasochism: Powerful pleasures (pp. 189-216) Binghamton, NY: Harrington Park Press.

Sagarin, B. J., Cutler, B., Cutler, N., LawlerSagarin, K. A., \& Matuszewich, L. (2009) Hormonal changes and couple bonding in consensual sadomasochistic activity. Archives of Sexual Behavior, 38, 186200.

Schulhofer, S. J. (1998). Unwanted sex: The culture of intimidation and the failure of law. Cambridge, MA: Harvard University Press.

Sisson, K. (2007) The cultural formation of S/M: History and analysis. In D. Langdridge \& M. Barker (Eds.), Safe, sane and consensual: Contemporary perspectives on sadomasochism (pp. 10-34). New York, NY: Palgrave Macmillan.

Soble, A. (2008) Antioch's “sexual offense policy”: A philosophical exploration. In A. Soble \& N. Power (Eds.), The philosophy of sex: Contemporary readings (5th ed., pp. 459-477). Lanham, MD: Rowman \& Littlefield Publishers.

Tsaros, A. (2013) Consensual non-consent: Comparing EL James's Fifty Shades of Grey and Pauline Reage's Story of O. Sexualities, 16(6), 864-879.

Weinberg, J. D. (2016) Consensual violence: Sex, sports, and the politics of injury. Oakland, CA: University of California Press.

Weinberg, T. S. (1995) Sociological and social psychological issues in the study of sadomasochism. In T. S. Weinberg (Ed.), S\&M: Studies in dominance \& submission (pp. 289-303). Amherst, NY: Prometheus Books.

Williams, DJ., Thomas, J. N., Prior, E. E., \& Christensen, M. C. (2014) From "SSC” and "RACK" to the "4Cs": Introducing a new framework for negotiating BDSM participation. Electronic Journal of Human Sexuality, 17(5).

Williams, DJ, Thomas, J. N., Prior, E. E., \& Walters, W. (2015) Introducing a multidisciplinary framework of positive sexuality. Journal of Positive Sexuality, 1, 6-11.

Wright, S., Stambaugh, R. J., \& Cox, D. (2015) Consent violations survey. Retrieved from National Coalition for Sexual Freedom: https://www.ncsfreedom.org/keyprograms/consent-counts-64083/consentcounts-44979. 
Yung, C. R. (2015-2016) Rape law fundamentals. Yale Journal of Law and Feminism, 27(1), 1-46. 